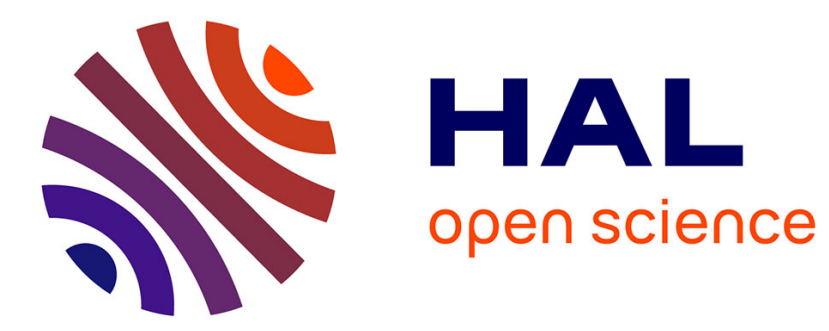

\title{
Hunting, Predation and Senescence in Boars
}

Marlène Gamelon

\section{To cite this version:}

Marlène Gamelon. Hunting, Predation and Senescence in Boars. Suresh I.S. Rattan. Encyclopedia of Biomedical Gerontology, Elsevier, 2020, 978-0-12-816076-3. 10.1016/b978-0-12-801238-3.11330-3 . hal-03282123

\section{HAL Id: hal-03282123 \\ https://hal.science/hal-03282123}

Submitted on 9 Aug 2021

HAL is a multi-disciplinary open access archive for the deposit and dissemination of scientific research documents, whether they are published or not. The documents may come from teaching and research institutions in France or abroad, or from public or private research centers.
L'archive ouverte pluridisciplinaire HAL, est destinée au dépôt et à la diffusion de documents scientifiques de niveau recherche, publiés ou non, émanant des établissements d'enseignement et de recherche français ou étrangers, des laboratoires publics ou privés. 


\title{
Hunting, predation and senescence in boars
}

\author{
Author Contact Information \\ Marlène Gamelon \\ Centre for Biodiversity Dynamics, Department of Biology, Norwegian University of Science \\ and Technology, 7491 Trondheim, Norway \\ marlene.gamelon@ntnu.no \\ $+4773596051$
}

\section{Keywords}

age-specific mortality, cause-specific mortality, competing risks, harvest, individual monitoring, life history strategy, sex-specific mortality, survival, Sus scrofa, ungulate

\begin{abstract}
Identifying the factors causing mortality over life is of great importance in gerontology, ecology and evolution. I first present some general methods to properly estimate age-related causes of mortality. Second, I report some of the studies that have quantified the main causes of mortality affecting wild boar over life, an emblematic game species that has dramatically increased in abundance and distribution across Europe. Hunting is the major cause of mortality, followed by natural mortality (e.g. starvation, senescence) and predation, all these factors of mortality being age- and/or sex-specific. Third, I discuss why it is important to examine how some sources of mortality can interact. Finally, I show how hunting can select for accelerated life history that allows wild boar to compensate high mortality probabilities with high reproductive output.
\end{abstract}

\section{Glossary}

Adults: Individuals older than 2 years of age.

Hunting mortality probability: the annual probability for an individual to die killed by hunting.

Juveniles: Individuals between 0 and 1 year of age, also called piglets.

Mortality due to predation: the annual probability for an individual to die killed by a nonhuman predator. Main predators for the wild boar are red foxes and wolves.

Natural mortality probability: the annual probability for an individual to die but not from human and non-human predation.

Natural survival probability: the probability for an individual to survive from one year to the next one, in absence of human and non-human predation.

Overall survival probability: the probability for an individual to survive from one year to the next one and thus not to die from hunting, predation or natural causes.

Subadults: Individuals between 1 and 2 years of age, also called yearlings. 
Identifying the factors causing mortality over life is of great importance in gerontology. This is indeed the first required step to understand the underlying mechanisms shaping mortality, such as genetic mechanisms and environmental factors. The work from Horiuchi and Wilmoth (1) is a nice illustrative study showing the major causes of death over life for females in Japan between 1951 and 1990. The same approach used on males and females in France between 1979 and 1994 indicates that malignant neoplasms, hypertensive disease or liver cirrhosis are some of the main causes of mortality between ages 30 and 54. At older ages, death rates increase drastically caused by infection diseases and heart failure (see Figure 2 in Horiuchi et al. (2) showing the age pattern of the cause-of-death structure).

A better understanding of the sources of mortality affecting individuals from birth to old ages is also crucial in ecology and evolution. For instance, Forrester and Wittmer (3) reviewed 48 studies to identify the major causes of mortality affecting mule deer and blacktailed deer Odocoileus hemionus at different ages. They found that predation is the main cause of mortality for all ages. Also, malnutrition as well as diseases can severely affect survival and more generally the growth of the populations. In addition of affecting population dynamics, the multiples sources of mortality act as selective pressures shaping life history traits. Studies led on harvested animal populations have provided valuable insight on the key role of age-specific mortality on life history evolution. For instance, there is growing evidence that high hunting mortality on the adult class can induce evolutionary changes such as earlier age at maturity and reduced body size (4). On the contrary, a removal of nonmature juvenile individuals may mimic natural mortality and predation pattern and thus limit undesirable evolutionary responses due to harvesting (5). Ultimately, a better knowledge of 
the causes of mortality affecting wild vertebrates over life might help elaborating appropriate management actions to control populations in a sustainable way.

As most ungulate populations in temperate areas, wild boar (Sus scrofa) abundance and distribution have increased over the last decades across Europe (6,7). Changes in agricultural practices, reduced hunting pressure, global change and land abandonment have favoured the expansion of this emblematic game species (8). When they overturn soil to feed, wild boars lead to important damages to crops and influence plant, animal, fungi and aquatic communities (see (9) for a review). They are also reservoirs of several diseases with some of them being possibly transmitted to humans, such as brucellosis or leptospirosis (10). Controlling wild boar populations has thus become an important goal for wildlife managers and hunting has long been proposed as a tool to achieve it.

Interestingly, this species exhibits an unusual life history strategy among ungulates rendering its regulation challenging. Firstly, females are particularly fecund, being able to produce up to 14 piglets in a single litter (11), at young ages (from their first year of life, 12) after having reached only $33-41 \%$ of their asymptotic adult body mass (13). Secondly, the generation time, i.e. the mean age of mothers at childbirth, is close to 2 years in some heavily hunted populations whereas it is around 6 years for similar-sized ungulates (14). This short generation time characterizing wild boar life history is typically observed in passerine birds or rodents. This indicates an especially fast turnover, with compensation for reduced survival in heavily hunted environment by reallocation of resources to reproduction $(12,14)$.

The purpose of this chapter is to identify the sources of mortality affecting wild boar over life, discuss how they can interact and shape life history traits. First, I present some general methods to properly estimate age-related causes of mortality. Second, I report some of the studies that have quantified the main causes of mortality affecting wild boars from 
young to older ages. Based on this literature survey, I discuss the type of mortality an individual is likely to experience according to its age and sex. Third, I argue why it is important to examine how some sources of mortality can interact. Fourth, I discuss how wild boar population growth rates can increase despite a somewhat low survival.

\section{Estimating cause-specific mortality}

The multiple sources of mortality that affect human and non-human individuals compete and their probability of wining depends on the strength of the different causes of mortality (15). Statisticians have thus long been interested in properly decomposing mortality into its different sources, the so-called "competing risks".

Sometimes, the fate of an individual (i.e. alive or dead) and the cause of death are precisely known. This is the case in medicine, human demography, in plants and captive animal populations. Also, in free-ranging animals, the recent advances in GPS and radiotelemetry technology may allow to identify the cause of death (16). Estimating age- and cause-specific mortality probability is thus straightforward with classical competing risk statistical models (see (17) for a review of methods to estimate cause-specific mortality in presence of competing risks; see also the books from $(18,19))$.

However, in non-captive animal populations, knowing the fate of an individual is challenging. For instance, an individual alive is not necessarily detected by the observer. On top of that, when the individual dies, identifying the cause of death is difficult because death is never observed in a wild population. Thanks to the development of multi-state capturerecapture $(\mathrm{CR})$ models, estimating cause-specific mortality probability when detection is imperfect and the cause of death is unobservable is now possible (20). Briefly, these methods 
are applicable to the study of marked animals that are recaptured several times during their life and recovered from at least one known cause of mortality (hunting for instance, see $(12,21)$ for case studies on wild boar). For example, Koons et al. (22) estimated age- and cause-specific mortality probability, namely the mortality probability due to hunting vs. the mortality probability due to human-unrelated causes, on lesser snow geese Chen caerulescens caerulescens and roe deer Capreolus capreolus by fitting multi-state CR models. Noticeably, mortality probability, defined as the probability for an individual to die during a given time interval, is commonly used in the fields of statistical modelling of CR data. On the contrary, mortality hazard rate, corresponding to the latent intensity of deadly events that an individual is exposed to, is classically used in medicine and human demography (see (15) for a discussion on the use of mortality hazard rates instead of mortality probabilities).

\section{Hunting}

From a literature survey, I report some of the studies that have quantified the main causes of mortality affecting wild boars from young to older ages using individual monitoring (table).

$$
<\text { Table near here> }
$$

Hunting is one of the major causes of mortality for the wild boar in Europe $(7,23)$.

The annual probability for an individual to be killed by hunting ranges from 11 to almost $50 \%$ in the reviewed studies (table). It is noteworthy that this probability is often agedependent. For instance, thanks to a long-term individual monitoring and the use of CR models, it has been shown that this source of mortality increases with increasing ages in males at Châteauvillain in France (24). In the Nature Reserve of Somiedo in Spain, adults are also those that are preferentially removed by hunting (25). This age-specific pattern of 
human-induced mortality may be explained by the reluctance to shoot juveniles, a general feature observed among hunters (26). Moreover, in wild boar, the probability to be killed by hunting depends on the sex of the individual, subadult and adult males being more likely to die from hunting than females.

This sex-specific pattern of human-induced mortality may result from contrasting abilities to escape from hunters. Indeed, wild boar live in matrilineal social groups with one large female leading a group (27) composed of juveniles with limited movement abilities (28). Contrary to solitary subadult and adult males, family groups tend to favour coppice habitats rather than bushlands during the hunting season (29). This can explain why subadult and adult males are more likely to be hunted than females. Sex-specific patterns of humaninduced mortality may also simply result from hunting rules that orientate hunting pressure on individuals with specific phenotypic characteristics. At Châteauvillain in France for instance, hunters have to pay a financial penalty if they shoot females larger than $50 \mathrm{~kg}(30)$. As a consequence, they prefer shooting a solitary male instead of shooting in a group, thus increasing mortality on subadult and adult males and relaxing the hunting pressure on adult females.

\section{Predation}

In some of the studied areas, human is not the only predator. In one Italian study site where both red foxes (Vulpes vulpes) and wolves (Canis lupus) are present, the monitoring of 164 wild boars tagged with radio-collars or transmitters equipped with a mortality sensor has shown that 2 of them died from predation (table, 28). In Poland, the analysis of wolf fecal samples has confirmed that wild boar is part of the wolf diet (31). In a recent review, Mori et al. (32) highlights that wild boar even constitutes the largest frequency of ungulate prey in 
wolf diet across Italy, before roe deer, red deer (Cervus elaphus) and livestock (32).

167 However, for the wild boar, mortality due to predation does not exceed 0.06 and thus remains small compared with human-induced mortality (table). Remarkably, this cause of mortality mainly affects wild boar at young ages. In Italy, they represent $77 \%$ of the wolf diet and this proportion even reaches $94 \%$ in Poland. Once again, such an age-specific pattern of predatorpredator.

\section{Other sources of mortality}

Wild boar can die from natural causes (i.e. not from human or non-human predation).

Natural mortality remains low, especially at adult stages (see table), translating to high natural survival. This is expected among ungulates, where the average natural adult survival probability was estimated to be 0.88 in males (see (36) for an analysis among 18 species) and may exceed 0.95 in females (34). The reported studies (table) provide estimates of natural survival at adulthood but age-specific survival patterns are ignored. However, a decline of natural survival with increasing ages (hereafter actuarial senescence) may occur as a result of the decline of the forces of natural selection with age (35), the selection of genes with a beneficial effect early in life that are deleterious later on (36) as well as high fertility translating to high rate of senescence (37). exception (39). Indeed, during an 18-year period at Castelporziano in Italy, 1783 juveniles and subadults were marked with ear-tags, released after handling and recaptured later on. The three oldest monitored individuals were 13 years of age. Thanks to this long-term individual monitoring, we estimated natural survival probabilities for each age and sex (39). We found a 
decrease of survival with age from age 3 onwards, with males exhibiting lower natural survival than females. Sex-specific reproductive tactics that increase mortality risks for males (40) can explain this between-sex difference. Also, harsh environmental conditions such as droughts may affect male survival stronger than female survival (33). However, it is noteworthy that this between-sex difference in adult survival remains quite weak (about $10 \%$, as in humans). Compared to other ungulates, wild boar females have earlier actuarial senescence for their body size. The high and early fertility of wild boar females may advance the age from which the decline of the forces of natural selection occurs (39).

In the first year of life, natural mortality can be higher than at adulthood (table). At Castelporziano for instance, juvenile survival probability was only $0.68[0.64 ; 0.72]$ (39). The major cause of natural mortality that has been identified is caused by severe winters (see $(41,42)$ for large-scale studies). Snow cover and low temperatures make food resources in the soil hardly accessible and increase juvenile mortality through disease and/or starvation. For some authors, milder winters and thus enhanced juvenile survival might explain the recent expansion of the species observed in the last decades (42). At Castelporziano, characterized with a typical Mediterranean climate, severe droughts might explain such a low piglet survival (43). In the second year of life, we found that natural survival reaches up to 0.85 $[0.77 ; 0.91]$ for females and drops to 0.57 [0.50; 0.64] for males. Such a high natural mortality for subadult males has already been reported in another site, at Châteauvillain in France (12). At this period of their life, males often disperse from their natal area to become solitary (44) and face with particularly increased mortality risks (e.g. starvation, collision with vehicles).

\section{Interaction between causes of mortality}



risks due to starvation and collision with vehicles for males than for females. Finally, they depend on the location of the studied population. For instance, the probability of dying from starvation because of winter harshness or from predation by wolves obviously depends on the study area.

$<$ Figure near here>

Importantly, these sources of mortality can be additive. Basically, it means that they are independent on each other and the overall mortality probability corresponds to the sum of all causes of mortality. In other words, an individual that dies from hunting would have survived in absence of hunting. But sources of mortality can be dependent on each other and interact. They might be compensatory, i.e. negatively correlated such as the overall mortality probability is lower than the sum of all causes of mortality. For instance, in a harvested duck population, Hepp et al. (45) showed that the individuals with the lowest body condition and thus with the lowest natural survival were more likely to be killed by hunting. In that case, an increase of hunting mortality leads to a reduction in natural mortality because the "strongest" individuals remain in the population. In that respect, predation by non-human predators is directly comparable, because it mainly affects vulnerable individuals in a population such as juveniles and senescents that often exhibit the highest natural mortality probability. Also, an increase of hunting mortality or mortality due to predation might reduce population density and thus disease transmission or competition among individuals. This ultimately leads to a decrease of natural mortality (46). Sources of mortality may be depensatory, i.e. positively correlated such as the overall mortality probability is higher than the sum of all causes of 
mortality. In that case, hunting can increase the mortality due to other causes. For instance, trophy hunting that aims at removing individuals with the largest horns/antlers potentially removes the individuals that perform the best in the population (47), leading to an increase of natural survival. Hunting might also influence the way individuals use their habitat. In willow ptarmigan Lagopus lagopus for instance, individuals spend more time in dense forests where foraging opportunities and availability of food resources are limited, thus leading to a decrease of body condition (48) and potentially high natural mortality. This change of habitat also increases the risk of predation (48). As a consequence, understanding how hunting interacts with other causes of mortality has become a central goal in animal ecology ((49), see e.g. (50) for a case study on willow ptarmigan).

In wild boar, whether mortalities are additive, compensatory or depensatory is a question that has been addressed in the population of Châteauvillain, in France. In that area, hunting constitutes the main source of mortality, followed by natural mortality (see table). Servanty et al. (21) found that these two sources of mortality are depensatory, natural mortality increasing with hunting mortality. Several factors can explain this result. First, selective hunting with the removal of the "best" individuals in the population may lead to increased natural mortality probability. However, hunters are posted around a given area and wait for animals startled by beaters and dogs. It is thus unlikely that they actually assess the phenotypic quality of the individuals when they are flushed out of the vegetation. Second, increased emigration in response to hunting can wrongly be interpreted as higher natural mortality. However, wild boar is sedentary (44) and it is unlikely that increasing hunting pressure is associated with increasing emigration rates. The only plausible explanation for an increased natural mortality with high hunting mortality is crippling loss. Individuals wounded or killed by hunting but never retrieved and recovered by hunters are considered as dead from natural causes. This can explain higher mortality probabilities when the probability to be 
killed by hunting is high (21). Whether depensatory mortalities are a common feature among wild boar populations or are specific to the studied population remains to be investigated.

\section{Hunting mortality and life history strategy}

Wild boar survival is strongly affected by hunting at all ages. In addition, predation, starvation, disease, collision with vehicles and finally senescence at older ages are additional sources of mortality for the species. All these causes of mortality may result in a particularly low overall survival probability. At Châteauvillain in France, overall survival probability is close to 0.45 for females and drops to 0.23 for adult males (24) leading to a somewhat short lifespan for such a long-lived species. In that context, one can wonder how wild boar numbers can still increase throughout Europe despite such a low overall survival.

This is because fecundity has become the focus of all selective pressures and particularly of hunting pressure. At Châteauvillain in France, birth dates have advanced by up to 12 days in a 22 -year period, selected by a high hunting pressure. This allows juveniles born early in the season, to grow for longer and thus reach the threshold body mass to reproduce early in life, in their first year of life (12). These findings of earlier age at first breeding are in line with a demographic analysis (see 14) that has compared two wild boar populations in contrasting environments: the French population suffering from a high hunting pressure and the lightly hunted Italian population at Castelporziano in Italy (see table). This analysis shows that the lightly hunted population has a typical demography of long-lived species with a high contribution of adult survival to the population growth rate and a generation time of 3.6 years. However, the heavily hunted population has a typical demography of short-lived species such as passerines, with the highest contribution for juvenile survival and exhibits an accelerated life history with a shorter generation time close to 2 years (14). Therefore, in 
environments characterized with a hunting mortality probability, wild boar females compensate by reallocating resources to reproduction early in life. This explains why an increase of hunting mortality probability does not translate to reduced population growth rates in wild boar, contrary to other ungulate species such as roe deer. In that respect, wild boar exhibits an unusual life history strategy among ungulates.

\section{References}

1. Horiuchi S, Wilmoth JR. Age patterns of the life table aging rate for major causes of death in Japan, 1951-1990. J Gerontol A Biol Sci Med Sci. 1997;52(1):B67-77.

2. Horiuchi S, Finch CE, Meslé F, Vallin J. Differential Patterns of age-related mortality increase in middle age and old age. J Gerontol Ser A. 2003;58(6):B495-507.

3. Forrester TD, Wittmer HU. A review of the population dynamics of mule deer and black-tailed deer Odocoileus hemionus in North America. Mammal Rev. 43(4):292-308.

4. Proaktor G, Coulson T, Milner-Gulland EJ. Evolutionary responses to harvesting in ungulates. J Anim Ecol. 2007;76(4):669-78.

5. Milner JM, Bonenfant C, Mysterud A. Hunting Bambi - evaluating the basis for selective harvesting of juveniles. Eur J Wildl Res. 2011;57(3):565-74.

6. Apollonio M, Andersen R, Putman R. European ungulates and their management 21st century. Cambridge University Press. 2010.

7. Massei G, Kindberg J, Licoppe A, Gačić D, Šprem N, Kamler J, et al. Wild boar populations up, numbers of hunters down? A review of trends and implications for Europe. Pest Manag Sci. 2015;71(4):492-500.

8. Massei G, Genov PV. The environmental impact of wild boar. Galemys Bol Inf Soc Esp Para Conserv Estud Los Mamíferos. 2004;16(1):135-45.

9. Barrios-Garcia MN, Ballari SA. Impact of wild boar (Sus scrofa) in its introduced and native range: a review. Biol Invasions. 2012;14(11):2283-300.

10. Meng XJ, Lindsay DS, Sriranganathan N. Wild boars as sources for infectious diseases in livestock and humans. Philos Trans R Soc B Biol Sci. 2009;364(1530):2697-707.

11. Servanty S, Gaillard J-M, Allainé D, Brandt S, Baubet E. Litter size and fetal sex ratio adjustment in a highly polytocous species: the wild boar. Behav Ecol. 2007;18(2):427-32. 
12. Gamelon M, Besnard A, Gaillard J-M, Servanty S, Baubet E, Brandt S, et al. High hunting pressure selects for earlier birth date: wild boar as a case study. Evolution. 2011;65(11):3100-12.

13. Servanty S, Gaillard J-M, Toïgo C, Brandt S, Baubet E. Pulsed resources and climate-induced variation in the reproductive traits of wild boar under high hunting pressure. J Anim Ecol. 2009;78(6):1278-90.

14. Servanty S, Gaillard J-M, Ronchi F, Focardi S, Baubet E, Gimenez O. Influence of harvesting pressure on demographic tactics: implications for wildlife management. J Appl Ecol. 2011;48(4):835-43.

15. Ergon T, Borgan $\varnothing$, Nater CR, Vindenes $Y$. The utility of mortality hazard rates in population analyses. Methods Ecol Evol. 2018;0(ja).

16. Tomkiewicz SM, Fuller MR, Kie JG, Bates KK. Global positioning system and associated technologies in animal behaviour and ecological research. Philos Trans R Soc Lond B Biol Sci. 2010;365(1550):2163-76.

17. Heisey DM, Patterson BR. A review of methods to estimate cause-specific mortality in presence of competing risks. J Wildl Manag. 2006;70(6):12.

18. Crowder MJ. Classical competing risks. CRC Press; 2001.

19. Collett D. Modelling survival data in medical research. CRC Press. Vol. Third Edition. 2014.

20. Pradel R. Multievent: an extension of multistate capture-recapture models to uncertain states. Biometrics. 2005;61(2):442-7.

21. Servanty S, Choquet R, Baubet E, Brandt S, Gaillard J-M, Schaub M, et al. Assessing whether mortality is additive using marked animals: a Bayesian state-space modeling approach. Ecology. 2010;91(7):1916-23.

22. Koons DN, Gamelon M, Gaillard J-M, Aubry LM, Rockwell RF, Klein F, et al. Methods for studying cause-specific senescence in the wild. Methods Ecol Evol. 2014;5(9):924-933.

23. Keuling $\mathrm{O}$, Baubet E, Duscher A, Ebert C, Fischer C, Monaco A, et al. Mortality rates of wild boar Sus scrofa L. in central Europe. Eur J Wildl Res. 2013;59(6):805-14.

24. Toïgo C, Servanty S, Gaillard J-M, Brandt S, Baubet E. Disentangling natural from hunting mortality in an intensively hunted wild boar population. J Wildl Manag. 2008;72(7):1532-9.

25. Nores C, Llaneza L, Álvarez Á. Wild boar Sus scrofa mortality by hunting and wolf Canis lupus predation: an example in northern Spain. Wildl Biol. 2008;14(1):44-51.

26. Sæther B-E, Engen S, Solberg EJ. Effective size of harvested ungulate populations. Anim Conserv. 2009;12(5):488-95.

27. Kaminski G, Brandt S, Baubet E, Baudoin C. Life-history patterns in female wild boars (Sus scrofa): mother-daughter postweaning associations. Can J Zool. 2005;83(3):474-80.

28. Merli E, Grignolio S, Marcon A, Apollonio M. Wild boar under fire: the effect of spatial behaviour, habitat use and social class on hunting mortality. J Zool. 2017;303(2):155-64. 
29. Saïd S, Tolon V, Brandt S, Baubet E. Sex effect on habitat selection in response to hunting disturbance: the study of wild boar. Eur J Wildl Res. 2012;58(1):107-15.

30. Gamelon M, Gaillard J-M, Servanty S, Gimenez O, Toïgo C, Baubet E, et al. Making use of harvest information to examine alternative management scenarios: a body weight-structured model for wild boar. J Appl Ecol. 2012;49(4):833-41.

31. Jędrzejewski Wł, Jędrzejewska B, Okarma H, Schmidt K, Zub K, Musiani M. Prey selection and predation by wolves in BiałowieŻa Primeval Forest, Poland. J Mammal. 2000;81(1):197-212.

32. Mori E, Benatti L, Lovari S, Ferretti F. What does the wild boar mean to the wolf? Eur J Wildl Res. 2017;63(1):9.

33. Toïgo C, Gaillard J-M. Causes of sex-biased adult survival in ungulates: sexual size dimorphism, mating tactic or environment harshness? Oikos. 2003;101(2):376-84.

34. Gaillard J-M, Festa-Bianchet M, Yoccoz NG, Loison A, Toïgo C. Temporal variation in fitness components and population dynamics of large herbivores. Annu Rev Ecol Syst. 2000;31(1):36793.

35. Medawar PB. An unsolved problem of biology. Lewis, London; 1952.

36. Williams GC. Pleiotropy, natural selection, and the evolution of senescence. Evolution. 1957;11(4):398-411.

37. Hamilton WD. The moulding of senescence by natural selection. J Theor Biol. 1966;12(1):12-45.

38. Nussey DH, Froy H, Lemaître J-F, Gaillard J-M, Austad SN. Senescence in natural populations of animals: widespread evidence and its implications for bio-gerontology. Ageing Res Rev. 2013;12(1):214-25.

39. Gamelon M, Focardi S, Gaillard J-M, Gimenez O, Bonenfant C, Franzetti B, et al. Do age-specific survival patterns of wild boar fit current evolutionary theories of senescence? Evolution. 2014;68(12):3636-3643.

40. Bonduriansky R, Maklakov A, Zajitschek F, Brooks R. Sexual selection, sexual conflict and the evolution of ageing and life span. Funct Ecol. 2008;22(3):443-53.

41. Melis C, Szafrańska PA, Jędrzejewska B, Bartoń K. Biogeographical variation in the population density of wild boar (Sus scrofa) in western Eurasia. J Biogeogr. 33(5):803-11.

42. Vetter SG, Ruf T, Bieber C, Arnold W. What is a mild winter? regional differences in withinspecies responses to climate change. PLOS ONE. 2015;10(7):e0132178.

43. Focardi S, Gaillard J-M, Ronchi F, Rossi S. Survival of wild boars in a variable environment: unexpected life-history variation in an unusual ungulate. J Mammal. 2008;89(5):1113-23.

44. Truvé J, Lemel J. Timing and distance of natal dispersal for wild boar Sus scrofa in Sweden. Wildl Biol. 2003;9(1):51-7.

45. Hepp GR, Blohm RJ, Reynolds RE, Hines JE, Nichols JD. Physiological condition of autumn-banded mallards and its relationship to hunting vulnerability. J Wildl Manag. 1986;50(2):177-83. 
46. Boyce MS, Sinclair ARE, White GC. Seasonal compensation of predation and harvesting. Oikos. 1999;87(3):419-26.

47. Mysterud A, Bischof R. Can compensatory culling offset undesirable evolutionary consequences of trophy hunting? J Anim Ecol. 2010;79(1):148-60.

48. Brøseth H, Pedersen HC. Disturbance effects of hunting activity in a willow ptarmigan Lagopus lagopus population. Wildl Biol. 2010;16(3):241-8.

49. Péron G. Compensation and additivity of anthropogenic mortality: life-history effects and review of methods. J Anim Ecol. 2013;82(2):408-17.

50. Sandercock BK, Nilsen EB, Brøseth $\mathrm{H}$, Pedersen $\mathrm{HC}$. Is hunting mortality additive or compensatory to natural mortality? Effects of experimental harvest on the survival and causespecific mortality of willow ptarmigan. J Anim Ecol. 2011;80(1):244-58. 


\begin{tabular}{|c|c|c|c|c|c|c|}
\hline Population & Hunting & Predation & Others & Age-related variation & Sex-related variation & Reference \\
\hline $\begin{array}{l}\text { Castelporziano, } \\
\text { Italy }\end{array}$ & $11 \%$ & $0 \%$ & $32 \%$ & $\begin{array}{l}\text { Hunting: } \\
\text { "Harvest rates were highest } \\
\text { for juveniles and subadults, } \\
\text { albeit for juveniles the } \\
\text { proportion harvested } \\
\text { alternated between very low } \\
(>2 \%) \text { to moderately high } \\
(10-15 \%) \text { in different years." } \\
\text { Others: } \\
\text { "for females, [natural] } \\
\text { survival was constant among } \\
\text { age classes, [natural] survival } \\
\text { of males differed among age } \\
\text { classes". }\end{array}$ & $\begin{array}{l}\text { Hunting: } \\
\text { "The proportion of males } \\
\text { harvested was always larger } \\
\text { than the proportion of } \\
\text { females, indicating a higher } \\
\text { harvest probability for } \\
\text { males". } \\
\text { Others: } \\
\text { "[natural] survival of males } \\
\text { and females differed only for } \\
\text { yearlings". }\end{array}$ & (43) \\
\hline $\begin{array}{l}\text { Nature Reserve of } \\
\text { Somiedo, Spain }\end{array}$ & $12 \%$ & $4.5 \%$ & NA & $\begin{array}{l}\text { Hunting: } \\
\text { "the mortality caused by } \\
\text { hunting drives tends to affect } \\
\text { the adult age groups more". } \\
\text { Predation: } \\
\text { "Wolf exerts a higher } \\
\text { pressure on juveniles rather } \\
\text { than on adults". }\end{array}$ & NA & $(25)$ \\
\hline $\begin{array}{l}\text { Tuscan Apennines, } \\
\text { Italy }\end{array}$ & $45.6 \%^{1}$ & $\begin{array}{l}2 \text { individuals out } \\
\text { of } 105 \text { during a } \\
\text { 9-year period }\end{array}$ & $\begin{array}{l}1 \text { individual out } \\
\text { of } 105 \text { during a 9- } \\
\text { year period }\end{array}$ & $\begin{array}{l}\text { Hunting: } \\
\text { "subadult wild boars, no matte } \\
\text { significantly higher probability } \\
\text { piglets." }\end{array}$ & $\begin{array}{l}\text { their sex, had a slightly } \\
\text { to be killed than adults and }\end{array}$ & $(28)$ \\
\hline
\end{tabular}




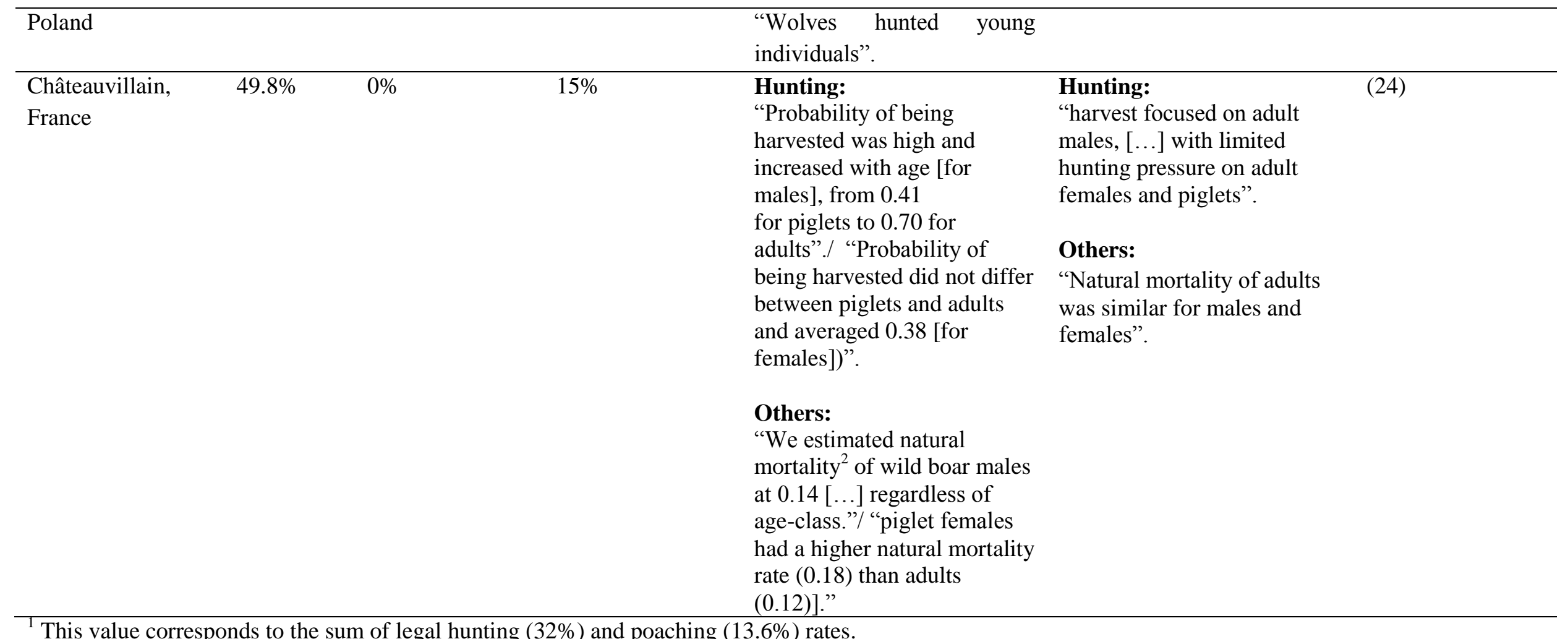

This value corresponds to the sum of legal hunting (32\%) and poaching (13.6\%) rates.

${ }^{2}$ Natural mortality corresponds to mortality excluding hunting mortality. 
413 Figure - Wild boar life cycle showing the causes of mortality affecting wild boar over life

414 (from left to right) in males (upper plot) and females (lower plot). The font size indicates the

415 relative importance of each cause of mortality (small font size corresponds to low importance

416 and large font size to high importance).

417

418
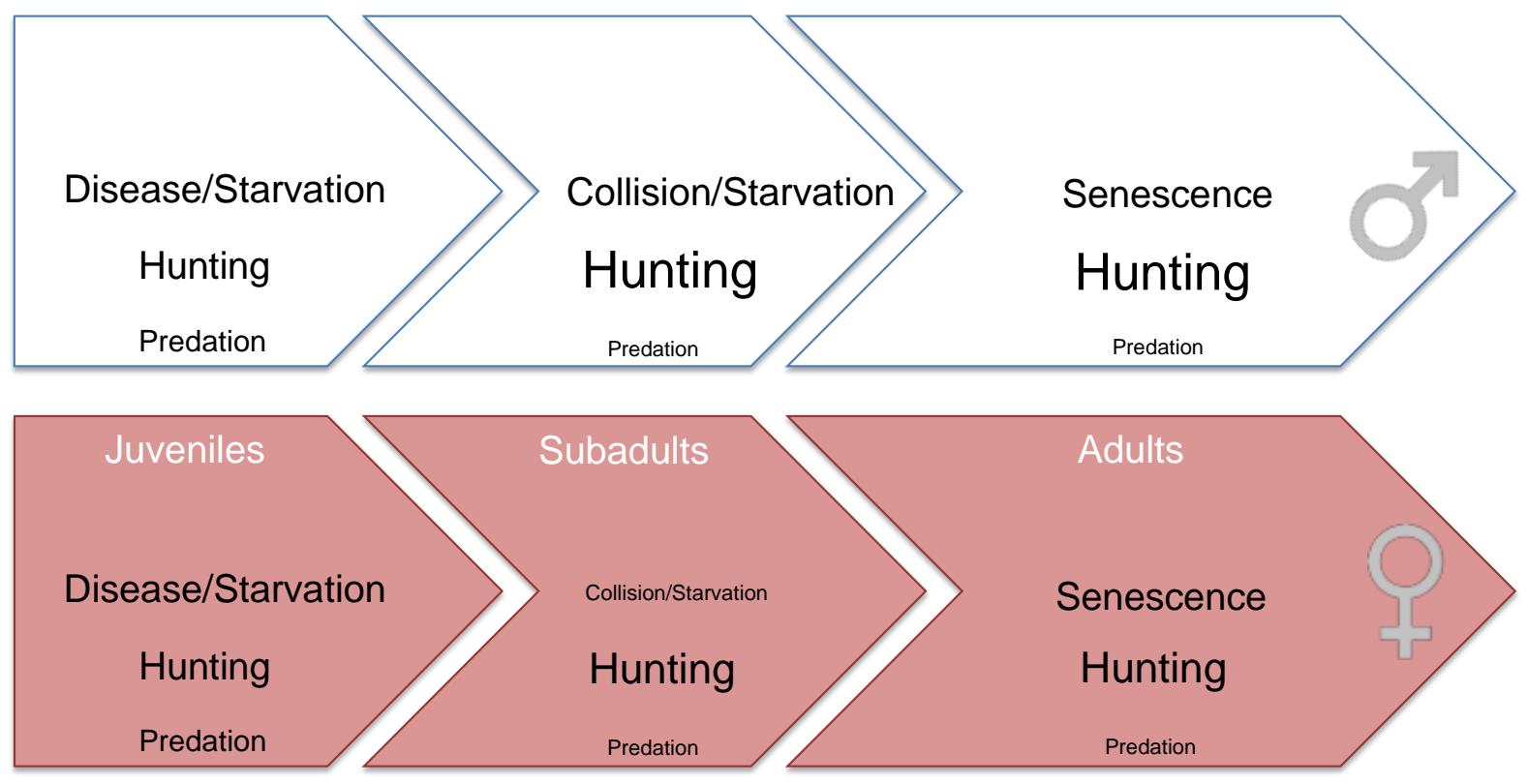

419

420

421

422

423

424

425

426

427 